\title{
REFLEXIONES ULTERIORES SOBRE INCONSTITUCIONALIDAD Y DEROGACIÓN*
}

\author{
Claudina Orunesu** \\ Jorge L. Rodríguez** \\ Germán Sucar***
}

\section{Introducción}

Es un honor para nosotros el que profesores de la talla de Javier EzQUIAGA Ganuzas, Ricardo Guastini y Ulises SChmill hayan dedicado su atención a las ideas que expusiéramos en nuestro trabajo "Inconstitucionalidad y Derogación". También nos sentimos honrados, pero al mismo tiempo orgullosos, de que quien fuera en el pasado nuestro alumno y hoy compañero de trabajo, Pablo PEROT, escribiera igualmente sus observaciones al respecto. El análisis de tales comentarios y críticas, así como los formulados en comunicaciones personales por Eugenio Bulygin, Jordi Ferrer, Juliano Maranhao y Pablo NaVArRo, nos han permitido repensar algunos puntos sobre el tema, y el presente trabajo es el fruto de tales reflexiones. En él no se pretende ofrecer una respuesta a todas las cuestiones en discusión, sino sólo avanzar algunas ideas adicionales, básicamente respecto de la distinción entre la inconstitucionalidad de una norma jurídica y su declaración por un órgano de control, el nexo que media entre tal distinción y la concepción que se adopte respecto de la interpretación de las normas y ciertos aspectos vinculados con la dinámica de los sistemas constitucionales.

\section{Existencia, regularidad y aplicabilidad de las normas jurídicas}

KeLSEN advirtió la dificultad que suponía, en el marco de su teoría, dar cuenta de las denominadas "normas inconstitucionales", esto es, explicar cómo es posible que normas irregularmente creadas produzcan efectos jurídicos en tanto su irregularidad no haya sido declarada por el órgano competente. Tal como lo expone SCHMILL, KelSEN identifica la regularidad en la creación de las normas, la existencia en el sentido de pertenencia a un sistema y la "validez", entendida esta última expresión como referida a la fuerza obligatoria de las normas. De manera que todas y sólo las normas que pertenecen a un sistema jurídico poseerían fuerza obligatoria y todas y sólo las normas que han sido regularmente creadas pertenecerían a un sistema. Si esto es así, caben diferentes caminos para dar cuenta del problema: 
(1) admitir que puede haber normas que poseen fuerza obligatoria pese a no haber sido regularmente creadas, conservando, no obstante, la identidad entre pertenencia y fuerza obligatoria. Desde este punto de vista, una norma inconstitucional podría tener fuerza obligatoria, en cuyo caso sería parte del derecho pese a su irregularidad, con lo que la creación regular no podría interpretarse como condición necesaria de la pertenencia a un sistema. (Este parece ser el camino elegido por GUASTINI).

(2) admitir que puede haber normas que poseen fuerza obligatoria pese a no haber sido regularmente creadas, conservando, no obstante la identidad entre pertenencia y regularidad. Desde este punto de vista, una norma inconstitucional podría tener fuerza obligatoria pese a no formar parte del sistema jurídico.

(3) admitir que puede haber normas que poseen fuerza obligatoria pese a no haber sido regularmente creadas, rechazando además la identidad entre pertenencia y fuerza obligatoria y entre pertenencia y regularidad. Desde este punto de vista, una norma inconstitucional podría tener fuerza obligatoria y ello no prejuzgaría sobre si forma o no parte del sistema. (Este es el punto de vista que defendimos en nuestro trabajo).

(4) mantener la triple identidad entre pertenencia, fuerza obligatoria y regularidad, lo que obligaría a considerar regularmente creadas a las normas inconstitucionales.

Esta última es la salida "heroica" -empleando la vívida expresión de Schmill- escogida por KeLSEN con su cláusula alternativa tácita. Claramente parece la más contraintuitiva de las cuatro, pero no ahondaremos aquí las críticas ya dirigidas contra ella.

GUASTINI considera como un pseudo-problema el de cómo explicar que una norma irregularmente creada produzca efectos jurídicos. Sostiene que, salvo que se identifique la "validez" de una norma, entendida como ausencia de vicios, con su aplicabilidad o fuerza obligatoria, no habría nada de misterioso en la posible aplicabilidad de las normas inválidas. Ahora bien, a juicio del profesor italiano, una norma inválida, en tanto su invalidez no haya sido reconocida por el órgano competente, pertenece al sistema. La promulgación efectiva por un órgano prima facie competente sería condición suficiente de la pertenencia al sistema jurídico. A su criterio la mejor manera de explicar el hecho de que una norma irregular pueda producir efectos jurídicos es que ella pertenece al sistema.

Bajo esta intelección, nos atribuye la desaconsejable tesis de identificar regularidad en la creación con pertenencia al sistema jurídico. En realidad, creemos que la regularidad en la creación de una norma no es condición necesaria 
de su pertenencia a un sistema, al menos en razón de la existencia de normas soberanas, las que si bien integran el sistema no pueden reputarse regularmente creadas. En cuanto a si es condición suficiente, debe distinguirse la cuestión según se adopte la reconstrucción del orden jurídico depurado o la del orden jurídico no depurado. La regularidad formal es condición suficiente de la pertenencia al orden jurídico no depurado. En cambio, para determinar la pertenencia al orden jurídico depurado, lo que constituye condición suficiente es la conjunción de la regularidad formal y material. En nuestro análisis del problema empleamos justamente la distinción entre "validez" -en el sentido de regularidad en la creación- y aplicabilidad de las normas para llegar a la conclusión que GUASTINI señala. De manera que no advertimos diferencia alguna en este punto con las ideas del profesor italiano.

Pero en nuestro criterio, no sólo no cabe asimilar aplicabilidad con regularidad, sino tampoco con pertenencia. Una norma puede producir efectos jurídicos sin pertenecer al derecho (tal el caso de las normas de un sistema extranjero declaradas aplicables en un país en virtud de sus normas de derecho internacional privado). Además, GUASTINI no parece percatarse de que es posible, por ejemplo, que un juez aplique de hecho una norma a un caso individual respecto del cual resulta inaplicable. Desde luego que puede ocurrir que una norma irregular sea aplicable, pero también puede ocurrir que una norma que no es en absoluto aplicable debido a su irregularidad sea, sin embargo, aplicada. Así, una sentencia que adopta como fundamento una norma general que es inconstitucional por ser su contenido incompatible con una norma constitucional, no es aplicable en ningún sentido para un juez que, en el marco de un sistema de control difuso, tenga la obligación de abstenerse de aplicar normas inconstitucionales. En conclusión, nos parece no sólo desafortunado identificar creación regular con pertenencia sino también con aplicabilidad. Estas tres nociones se diferencian claramente en nuestro trabajo. Además, es importante distinguir aplicación de aplicabilidad. De acuerdo con esta última distinción, una norma inaplicable (sea válida o inválida), puede ser aplicada y producir así efectos jurídicos, así como puede ocurrir que una norma aplicable (sea válida o inválida) no sea aplicada.

\section{Inconstitucionalidad y control de constitucionalidad}

En nuestro trabajo tratamos de destacar las diferencias que median entre la inconstitucionalidad de una norma y la declaración de inconstitucionalidad hecha por cierto órgano competente de conformidad con las normas jurídicas. Respecto de la primera de estas dos nociones, distinguimos como es tradicional 
entre la inconstitucionalidad de una norma como producto de la incompatibilidad con normas constitucionales (inconstitucionalidad material), y la inconstitucionalidad de una norma por falta de satisfacción de las condiciones fijadas por las normas constitucionales respecto del acto de su promulgación (inconstitucionalidad formal). Con relación a este punto, EzQuIAGA expresa que en ciertos casos la inconstitucionalidad de una norma puede tener por causa la vulneración de las normas de producción jurídica relativas a la materia objeto de regulación. Un órgano podría regular materias para las que no está autorizado o no respetar los límites territoriales, personales o temporales establecidos por las normas de producción jurídica. Un supuesto semejante, a pesar de que tendría que ver con la materia regulada, no parecería encuadrable como inconstitucionalidad material, ya que si bien su apreciación exigiría evaluar la materia objeto de regulación, la inconstitucionalidad por esta causa sería independiente de la existencia de una incompatibilidad entre la norma en cuestión y la constitución. Esto demostraría que la separación entre inconstitucionalidad formal y material no sería tan tajante, puesto que para establecer la primera parecería inevitable asignar algún significado a la formulación normativa. Por ello, concluye que en muchas ocasiones la inconstitucionalidad, tanto formal como material, debe predicarse de formulaciones interpretadas.

La distinción propuesta por EZQUIAGA es correcta, y fue pasada por alto en nuestro trabajo. Estamos de acuerdo con su conclusión, con la salvedad de que no pretendimos afirmar que la inconstitucionalidad pudiera versar sobre formulaciones interpretadas o no interpretadas, sino más bien que, al hablarse de la inconstitucionalidad de las normas, siendo esta última expresión interpretable al menos en los dos modos expuestos, era menester analizar separadamente qué significaría decir que una norma es inconstitucional en uno y otro caso.

Respecto de la declaración de inconstitucionalidad por parte de un órgano del Estado, dijimos que entre ella y la inconstitucionalidad de una norma mediaba una relación semejante a la que existe entre la creencia en la verdad de una proposición y su verdad. Así como se puede creer en la verdad de una proposición falsa y en la falsedad de una proposición verdadera, análogamente, se puede declarar constitucional una norma inconstitucional así como declarar inconstitucional una norma ajustada a la constitución. Por el contrario, SCHMILL identifica inconstitucionalidad con declaración de inconstitucionalidad y sostiene por ello que no puede haber algo así como "inconstitucionalidad a priori". También como consecuencia de esto, considera que nuestra posición no es compatible con el positivismo. 
Por el contrario, pensamos que nuestra concepción es estrictamente positivista, de manera que, o bien SCHMILl ha malinterpretado el alcance de nuestras tesis, o bien no compartimos la misma caracterización del positivismo jurídico. Nos inclinamos más bien por la segunda de estas alternativas, dado que, según parece, "positivo" significa para Schmill resultante de una decisión autoritativa. Nosotros aceptamos la tesis de que todo derecho es derecho positivo, esto es, la tesis de las fuentes sociales. Pero de ella no se sigue en absoluto que no pueda introducirse la distinción conceptual que proponemos. Por otra parte, consideramos que el positivismo se encuentra ligado a una tradición política que pone énfasis en sostener que el contenido de un sistema jurídico positivo siempre se encuentra sujeto a crítica desde el punto de vista de la corrección moral o jurídica de sus normas, dado que ellas dependen de decisiones humanas y estas últimas pueden ser cuestionables. Desde este punto de vista, nos parece mucho más en línea con una concepción positivista del derecho el preservar la distinción entre inconstitucionalidad y declaración de inconstitucionalidad, puesto que pone énfasis en la posibilidad (lamentablemente registrada con demasiada frecuencia) de que las decisiones acerca de la constitucionalidad de las normas por parte de los órganos competentes sean objetables, tanto moral como jurídicamente. Claro que esto supondría la existencia de algún criterio de corrección para tales decisiones. En lo que a la moral concierne, ninguno de nosotros defiende la existencia de criterios objetivos de corrección normativa. Pero sobre la existencia de criterios jurídicos de corrección, creemos pertinente introducir algunas aclaraciones.

Según la concepción de SchmiLl, la norma creada de grada inferior no repite el contenido de la norma que la determina, sino que siempre hay un incremento en el contenido de la segunda respecto de la primera. Esta concepción del orden jurídico sería deudora de la postura filosófica de cuño coheniano según la cual sólo es aceptable en un sistema científico aquello que puede construirse desde su origen sobre la base de ciertas hipótesis. Trasladado este principio al ámbito jurídico, él importaría para SCHMILL no sólo que en la ciencia del derecho nada debe considerase como "dado", debiendo ser construido teóricamente, sino también que el derecho mismo debe ser entendido como un orden normativo que se crea y recrea en el tiempo. En consecuencia, no se podría considerar como perteneciente al derecho nada que no haya sido puesto o establecido por medio de un acto humano.

Así, la inconstitucionalidad de una norma sólo estaría "dada" a la ciencia jurídica si se han cumplido los requisitos y condiciones establecidos por el propio derecho, lo que implicaría que no existe algo parecido a una "inconstitucionalidad 
a priori", pues tal calificativo sólo podría emplearse cuando ella ha sido establecida de manera positiva en el proceso de progresiva individualización del orden jurídico. Antes de la adopción de la decisión por el órgano competente no podría afirmarse ni la constitucionalidad ni la inconstitucionalidad de una norma: tal decisión tendría un "carácter claramente constitutivo", siendo irrelevante cualquier otra opinión, puesto que no constituiría la determinación jurídicamente válida de la cuestión planteada.

Sobre tales bases, Schmill destaca lo que considera la "omisión fundamental" de nuestro ensayo: no relacionar la inconstitucionalidad con la anulabilidad de la norma viciada. Según SCHMILL, la ley promulgada es una norma existente, y la determinación de su inconstitucionalidad queda a cargo de los sujetos habilitados al efecto, $y$ "objetivamente hablando", ello se encuentra ligado "de manera esencial" con la anulabilidad: si no hay anulabilidad, no hay inconstitucionalidad. Siguiendo a KELSEN, entiende que una constitución que carezca de la garantía de anulabilidad de los actos inconstitucionales no es una constitución plenamente obligatoria en sentido técnico, puesto que equivaldría a poco más que unos buenos deseos desprovistos de fuerza obligatoria.

A fin de comparar su propuesta con la nuestra, es importante recordar que el problema bajo análisis es el siguiente: cómo explicar que una norma irregularmente creada produzca efectos jurídicos, en particular, cómo es posible que tal cosa ocurra antes de que el órgano competente se pronuncie respecto de la irregularidad. La respuesta de ScHMILL consiste en sostener que antes de la declaración del órgano competente no puede hablarse de irregularidad. Pero no puede negarse que la norma en cuestión o bien fue creada regularmente o bien fue creada irregularmente, y ello con total independencia de lo que en definitiva diga el órgano encargado del control de acuerdo con las normas del ordenamiento jurídico considerado. Por consiguiente, una primera razón por la que nos parece insatisfactoria esta salida es que prohibir estipulativamente que se hable de irregularidad antes de tal pronunciamiento importa solucionar el problema por definición: no hay irregularidad hasta tanto no exista pronunciamiento del órgano competente, razón por la cual no existe por definición el problema que aquí se analiza.

Además de suprimir el problema por definición, una segunda dificultad que afecta a la propuesta del profesor mexicano es la siguiente: si no puede hablarse de irregularidad antes de la declaración por el órgano competente, tampoco correspondería hablar de su regularidad. La sugerencia de SCHMILL no salva la identidad propuesta por KELSEN entre regularidad, pertenencia y fuerza 
obligatoria de las normas. Incluso suponiendo que una norma deba reputarse regularmente creada en tanto no exista un pronunciamiento relativo a la irregularidad de su creación, de todos modos desde este punto de vista, la irregularidad dependería del pronunciamiento del órgano de control que así lo dispone, mientras que nada semejante ocurriría respecto de su pertenencia al sistema ni de su fuerza obligatoria.

Una atención especial merece la tesis de Schmill de que las decisiones acerca de la inconstitucionalidad de las normas poseen "carácter constitutivo". Al respecto, SCHMILL destaca acertadamente que en nuestro trabajo no explicamos en forma debida la razón por la que consideramos incompatible atribuir carácter constitutivo a las decisiones judiciales sobre la inconstitucionalidad de las normas con la estructura jerárquica del orden jurídico. Si no lo hicimos es porque la razón nos pareció evidente. En un ejemplo simple: supóngase que el tribunal constitucional declara constitucional una norma que es lógicamente incompatible con preceptos constitucionales, y que a dicho pronunciamiento se le atribuye carácter constitutivo -lo que significa que una norma se considerará constitucional o no si y sólo si el tribunal constitucional así lo decide-. En tal hipótesis, no existirían otras jerarquías entre las normas jurídicas que aquellas que los jueces estén dispuestos a reconocer. Decir, por ejemplo, que la constitución es jerárquicamente superior a las leyes sólo significaría "la constitución es jerárquicamente superior a las leyes en la medida en que así lo decidan los jueces". No serán ya las normas jurídicas sino los jueces quienes establecerán si una norma ha sido o no creada regularmente, razón por la cual la idea de la estructura jerárquica del orden jurídico se tornaría una ficción.

Recuérdese que de conformidad con la idea kelseniana de la estructura jerárquica del orden jurídico, una norma sólo pertenece a determinado orden jurídico porque y en cuanto su producción se corresponde con una norma superior determinante. Si los pronunciamientos sobre la regularidad en la creación de normas se consideran constitutivos, entonces la única condición que debería satisfacerse para considerar a una norma regularmente creada es la existencia de un pronunciamiento del órgano pertinente que así lo establezca, con total independencia de su correspondencia o no con otra norma del orden. Contra esto no puede contestarse que los pronunciamientos de los órganos de control se fundan en la conformidad o no de la norma con normas jerárquicamente superiores y que por ello esto último no sería irrelevante. No puede argumentarse de este modo porque se reconocería en tal caso un criterio de corrección independiente de las decisiones de los órganos de control, cosa que resulta incompatible con la atribución de carácter constitutivo a los pronunciamientos 
sobre inconstitucionalidad.

A ScHMILL le parece evidente lo contrario -esto es, que el carácter constitutivo de los pronunciamientos sobre inconstitucionalidad y la estructura jerárquica del orden jurídico resultan perfectamente compatibles- básicamente porque cree que un pronunciamiento judicial sobre la inconstitucionalidad de una norma es dotado de sentido y efectos jurídicos en virtud de otras normas jurídicas, a las que por ello cabría interpretar como jerárquicamente superiores. Pero este argumento no desvirtúa lo dicho ya que ni siquiera podría sostenerse desde una perspectiva como la que él asume que las normas que atribuyen consecuencias jurídicas a los pronunciamientos judiciales sobre la inconstitucionalidad de las normas resulten de mayor jerarquía que esas decisiones. Ello así en tanto tal jerarquía también resultaría dependiente de su reconocimiento judicial.

Quizás pueda ayudar a comprender una concepción como la de SCHMILL adaptar un argumento que utiliza KeLSEN para justificar su idea del carácter constitutivo de las sentencias respecto de los hechos del caso:

1) Si es que la constitución debe ser aplicada, no puede valer cualquier opinión sobre la inconstitucionalidad de una ley: sólo puede valer una opinión.

2) La opinión que vale es la del órgano -y por el procedimientodeterminado por el propio orden jurídico.

3) Si los órganos en cuestión son los órganos jurisdiccionales, las opiniones acerca de la inconstitucionalidad de las leyes de otras personas podrán eventualmente fundar un recurso contra la decisión adoptada, pero cuando ella pasa en autoridad de cosa juzgada, no siendo posible revocarla mediante ningún otro procedimiento, esas otras opiniones "quedan excluidas", son jurídicamente irrelevantes.

Este parece ser el camino que elige SCHMILL para justificar que no existe algo así como "inconstitucionalidad a priori". Pero adviértase cuál es la conclusión a la que llega KeLSEN en su argumentación, proyectada ahora al problema de la inconstitucionalidad:

4) La norma constitucional no dice, por ejemplo, que si el legislador dicta una ley que lesiona el derecho a la información debe decretarse su inconstitucionalidad, sino que reza: "cuando el tribunal competente mediante el procedimiento determinado por el orden jurídico, ha establecido con fuerza de cosa juzgada que determinada ley lesiona el derecho a la información, el tribunal debe decretar su inconstitucionalidad".

En otras palabras, la constitución no dice más que lo que los jueces dicen que dice. Esta posición sólo es defendible sobre la base de una visión radicalmente 
indeterminista respecto de la interpretación de las normas constitucionales, y lleva a que el control de constitucionalidad no sea más que una suerte de poder de veto de los jueces sobre las normas que dicte el legislador. Si se rechaza esta postura extrema respecto de la interpretación de las normas constitucionales, si se admite que puede haber casos claros de inconstitucionalidad, la conclusión es inadmisible.

Dijimos que en una concepción como la defendida en nuestro trabajo, que distingue entre la inconstitucionalidad de una norma y la declaración de inconstitucionalidad por cierto órgano, se presupone la existencia de algún criterio jurídico de corrección de las decisiones sobre inconstitucionalidad. En otras palabras, se adopta una concepción de la interpretación de las normas constitucionales que rechaza la tesis de la indeterminación radical, según la cual toda interpretación es una invención del intérprete, esto es, que no hay nada objetivo en la operación de interpretación. Otra forma de plantear esta tesis es que no existiría ningún caso claro de aplicación de una norma. Si se sostiene la tesis de la indeterminación radical al menos respecto de las normas constitucionales, ello conduce a considerar que no existe ninguna norma que pueda ser calificada como incompatible con la constitución. Sólo si se parte de una idea semejante tiene sentido afirmar que los pronunciamientos sobre la inconstitucionalidad son constitutivos, y ello por cuanto las normas inconstitucionales no dirían nada en tanto no medie un pronunciamiento del órgano competente que precise su sentido. Si en cambio se rechaza la tesis de la indeterminación radical, y se admite la existencia de -al menos algunos- casos claros de inconstitucionalidad, existirá un criterio de corrección y, al menos en ciertos casos, podrá decirse que el órgano de control ha cometido un error al declarar la constitucionalidad o inconstitucionalidad de una norma.

De todos modos, lo más problemático de la posición bajo análisis no es que se asuma una concepción acerca de la interpretación de las normas constitucionales que no compartimos, sino que no se la mantenga consecuentemente. En efecto, la tesis de la indeterminación radical no puede conjugarse con la idea de que un pronunciamiento sobre la inconstitucionalidad de una norma es una forma especial de anularla debido a su irregularidad que garantiza la supremacía de la constitución.

KeLSEN sostiene que anular una norma significa privar a un acto, cuyo sentido subjetivo es una norma, del sentido objetivo que le da otra norma, esto es, poner término a la validez de esa norma mediante otra norma. Ahora bien, el sentido objetivo de un acto es aquel que, más allá de cuál haya sido la intención 
de quien lo produjo, corresponde asignarle en función de lo que una norma determina. No depende más que de esa norma, que funciona como esquema de explicitación conceptual y pauta objetiva de valoración. Dada la norma, cualquiera puede hacer esa evaluación. Tratándose de un acto de prescribir, que el sentido subjetivo de quien formula la prescripción se considere objetivamente como una norma $\mathrm{N}_{1}$ o no, depende de lo que determine otra norma $\mathrm{N}_{2}$. Otra norma, no lo que ciertas personas opinen al respecto, sea que se trate de los miembros del tribunal constitucional o de cualquier mortal. Ahora bien, es obvio que puede haber discrepancias de opinión entre distintas personas al respecto. En tal caso, puede ser que otra norma $\mathrm{N}_{3}$ establezca que tales diferencias deben ser dirimidas por el órgano $\mathrm{O}$. La pregunta clave es si puede admitirse o no la posibilidad de que $\mathrm{O}$ se equivoque en su decisión. Si se considera que sí, es porque se acepta que existe algún criterio objetivo de corrección: lo que la norma $\mathrm{N}_{2}$ dice, en la medida en que dice algo. Si se considera que no, entonces la decisión del órgano $\mathrm{O}$ es completamente discrecional al respecto. Pero entonces no hay criterio alguno de corrección, esto es, no hay norma $\mathrm{N}_{2}$ alguna que permita asignarle al acto de prescripción originario el sentido objetivo de ser una norma. A lo sumo existirá un texto desprovisto de todo significado en tanto éste no sea inventado por el órgano O. Esto equivale a decir que, pese a que el sentido subjetivo de quien emitió la prescripción haya sido dictar la norma $\mathrm{N}_{1}$, ese no es el sentido objetivo que corresponde asignarle de conformidad con la opinión de O: se habrá perdido toda noción de objetividad.

Si los pronunciamientos sobre inconstitucionalidad son constitutivos, la única condición a la que se supedita la anulación por el órgano competente es que éste así lo resuelva, no la regularidad o irregularidad de la norma de conformidad con la constitución. Manteniendo la terminología kelseniana, no puede sostenerse desde este punto de vista que un acto de prescribir adquiera el sentido objetivo de ser una norma en virtud de lo que disponen otras normas jerárquicamente superiores a su respecto -las normas constitucionales en nuestro caso-: lo único que contaría como relevante para considerar a una norma como regularmente dictada sería la decisión del órgano de control ya que las normas constitucionales serían moldes vacíos. Si se rechaza esto último, no puede defenderse el carácter constitutivo de los pronunciamientos sobre inconstitucionalidad.

Aunque no parece advertirlo -y al igual que la concepción de la interpretación jurídica defendida por KeLSEN-, la posición de SCHMILL supone una confusión entre lo que DwORKIN califica como "sentido fuerte" y "segundo sentido débil" de discrecionalidad. Del hecho de que una norma admita varias 
interpretaciones posibles -sentido fuerte de discrecionalidad- no se sigue que sólo una de ellas sea derecho positivo en virtud de que es la escogida con carácter definitivo por el órgano de aplicación -segundo sentido débil-. En lo concerniente a la inconstitucionalidad, del hecho de que las normas constitucionales admitan varias interpretaciones posibles no se sigue que sólo pueda hablarse de inconstitucionalidad cuando existe un pronunciamiento definitivo por parte del órgano de control y que la opinión de cualquier otra persona resulte "jurídicamente irrelevante".

En conclusión, a nuestro juicio el pronunciamiento sobre la inconstitucionalidad de una norma por parte de un órgano del Estado es un juicio complejo, constitutivo en cuanto a su inaplicabilidad (erga omnes o para el caso particular), pero respecto de la irregularidad que constituye su fundamento será declarativo o constitutivo según cuál sea la postura que se adopte respecto de la interpretación. Para los defensores de la tesis de la indeterminación radical, el pronunciamiento sobre inconstitucionalidad será constitutivo de la irregularidad, un punto de vista que resulta inconciliable con la idea de supremacía de la constitución. Cualquier postura que rechace la tesis de la indeterminación radical resulta compatible con la supremacía constitucional, pero inconciliable con la idea del carácter constitutivo de las decisiones sobre inconstitucionalidad.

\section{Dos modelos de orden jurídico}

En nuestro trabajo propusimos distinguir entre lo que calificamos como el modelo del orden jurídico depurado, según el cual el criterio de lex superior funcionaría ex ante, previniendo el ingreso de normas incompatibles con la constitución, del modelo del orden jurídico no depurado, según el cual el principio de lex superior funcionaría ex post, permitiendo el ingreso de normas materialmente inconstitucionales. Según este último, los conflictos generados se dirimirían en el nivel de la aplicabilidad de las normas a casos particulares.

GUASTINI sostiene que la identificación entre validez y pertenencia -que nos atribuye, pero que, como se dijo, no intentamos sostener- supone la adopción del modelo del orden jurídico depurado. Esto es correcto, aunque es menester aclarar que en nuestro trabajo no nos embarcamos en una defensa de ninguno de estos dos modelos. Por el contrario, nos limitamos a mostrar algunas de las diferentes consecuencias que se seguirían de la adscripción a uno u otro.

GUASTINI ofrece una interpretación de nuestra propuesta de distinción entre estos dos modelos de reconstrucción del orden jurídico como dos modos de 
organizar el control de constitucionalidad. La lectura de GUASTINI es viable toda vez que en ciertos sistemas jurídicos el control de constitucionalidad se efectiviza antes de la promulgación y en otros con posterioridad a ella. No obstante, no es esa la distinción que propusimos. Como se ha expresado, intentamos diferenciar claramente entre la inconstitucionalidad de una norma y la declaración de su inconstitucionalidad. Un pronunciamiento sobre la inconstitucionalidad de una norma sólo contingentemente tiene incidencia sobre la pertenencia de una norma a un sistema jurídico. Por consiguiente, ambas cuestiones no deberían ser confundidas. En otras palabras, ambos modelos de reconstrucción de los ordenamientos jurídicos resultan independientes de los mecanismos de control instrumentados. La utilidad de nuestra distinción puede considerarse un punto pendiente de demostración, pero su finalidad es distinta de la lectura que ofrece GuASTINI.

La observación que consideramos de mayor interés sobre este punto es la que ofrece Pablo Perot en el final de su artículo. Allí sostiene que presentamos la distinción como dos diversos esquemas teóricos de reconstrucción de los sistemas jurídicos. No obstante, se pregunta si estas dos alternativas no estarían más bien condicionadas por el contenido de las normas de los diferentes ordenamientos positivos. A su juicio, el problema podría plantearse del modo siguiente: la distinción entre el orden jurídico depurado y el no depurado se basaría en una diferente reconstrucción del criterio de legalidad. Desde este punto de vista, la diferencia radicaría en una lectura distinta de las reglas de competencia a las que hace referencia el criterio de legalidad: una que toma como condición de validez de las normas la compatibilidad entre ellas y las disposiciones constitucionales y otra que no considera tal condición. La pregunta sería entonces si la elección entre estas dos diversas lecturas no dependería de lo que establezcan las normas constitucionales que confieren competencia, cuestión que se encontraría a su criterio en el trasfondo de la controversia entre el positivismo excluyente y el incluyente.

Pensamos que nuestra distinción es independiente de la configuración concreta de los sistemas jurídicos. En otras palabras, con ella no pretendimos dar cuenta de diferencias que puedan registrarse entre los sistemas jurídicos existentes. La cuestión central es si se interpreta que un criterio para la resolución de conflictos entre normas como lex superior funciona como criterio de pertenencia de normas a los sistemas jurídicos o como criterio de aplicabilidad. Desde el primer punto de vista, una norma materialmente inconstitucional no forma parte del derecho. Desde el segundo, en cambio, ella ingresa en el sistema jurídico y el conflicto que provoca debe ser resuelto por el órgano de aplicación 
frente a los casos individuales. A primera vista, diríamos que ninguna formulación de las normas de competencia de un sistema jurídico condiciona una de estas dos posibles lecturas, y que todo lo que puede decirse en el lenguaje propio de una de ellas puede reinterpretarse satisfactoriamente desde la concepción alternativa. De todos modos, el interrogante planteado por PEROT es muy inteligente y parece prometedora la propuesta de explorar sus implicancias respecto de la disputa entre positivistas incluyentes y excluyentes. Pero no es éste el lugar para intentar internarnos en esa discusión.

\section{Derogación expresa y derogación tácita}

GuASTINI Considera que si derogar produce como efecto la expulsión del sistema de la norma derogada, entonces provoca su no pertenencia al sistema. Y si se interpreta que pertenencia equivale a validez, entonces la derogación produce la revocación de la validez, lo que volvería indistinguible dicha operación de la declaración de inconstitucionalidad. Por su parte, entiende que si se interpreta la noción de validez como referida a la ausencia de vicios, entonces se trataría de una propiedad que una norma posee o no posee, pero que no puede ser conferida ni revocada.

Coincidimos en esto puntualmente con el parecer de GuAstinI. Lo lamentable es que nos haya faltado la claridad expositiva necesaria para que el maestro italiano advirtiera que uno de los cometidos centrales de nuestro trabajo apuntaba justamente a distinguir los diferentes efectos de la declaración de inconstitucionalidad y la derogación. La única salvedad que podríamos formular en lo que a esto concierne es que, entre las diferencias que GUASTINI apunta entre derogación y declaración de inconstitucionalidad, señala que la declaración de inconstitucionalidad supone la invalidez de la norma y se funda en ella, mientras que la derogación puede operar sobre normas válidas o inválidas. En rigor, creemos que la declaración de inconstitucionalidad también puede operar sobre normas válidas o inválidas, por la sencilla razón de que el órgano de control puede equivocarse: puede declarar inconstitucional una norma válida o constitucional una norma inválida. En otras palabras, es correcto que la declaración de inconstitucionalidad se funda en la invalidez, pero no que supone la invalidez.

Tanto SCHMILl como GuAStiNI cuestionan el fenómeno, analizado en nuestro trabajo, de la derogación de normas implícitas y las posibles indeterminaciones que ella podría provocar. El primero porque sencillamente no admite la existencia de normas lógicamente derivadas, ya que ellas no serían normas positivas. El 
segundo, porque entiende que el razonamiento jurídico no sólo está regido por la lógica sino por el propio derecho, siendo posible que este último excluya la admisibilidad de ciertas inferencias que serían lógicamente válidas, así como que considere admisibles inferencias lógicamente inválidas. Como ejemplo de lo segundo alude a los razonamientos por analogía en los sistemas jurídicos -y para los sectores del derecho- en los que ellos se encuentran expresamente consentidos. Como ejemplo de lo primero ofrece el siguiente: si en un cierto sistema jurídico, de las normas $\mathrm{N}_{1}$ y $\mathrm{N}_{2}$ se sigue lógicamente una norma implícita $\mathrm{N}_{3^{\prime}}$ y con posterioridad se promulga una norma $\mathrm{N}_{4}$ incompatible con $\mathrm{N}_{3}$, entonces "mal que le pese a la lógica" $N_{3}$ no constituiría una inferencia admisible. De esto se seguiría que la derogación de una norma implícita no provocaría indeterminaciones $y$, en términos más generales, que un sistema jurídico no contendría junto a las normas expresas todas sus consecuencias lógicas, sino aquellas consecuencias lógicas que no estén "prohibidas" por normas expresas, más aquellas consecuencias no lógicas que, no obstante, sean consentidas por normas expresas.

Aquí, como en casi todas las diferencias que nos separan de GuAstinI, no podemos decir que la suya sea una reconstrucción incorrecta, pero sí que no es la única posible y que no la compartimos. Es cierto que en la mayoría de los sistemas jurídicos se admite a la analogía, al menos en ciertas áreas del derecho. ¿Indica esto que el derecho admite formas de inferencia lógicamente inválidas? No necesariamente: puede ser que frente a casos de lagunas normativas el derecho admita que el órgano de aplicación justifique su decisión en una norma creada en analogía con las soluciones previstas por otras normas del sistema. En tal caso, el derecho estará conformado por las normas explícitamente dictadas por las autoridades competentes más todas sus consecuencias lógicas pero, frente a casos de lagunas normativas, se admite que el órgano de aplicación está facultado para fundar su decisión en normas que, o bien no integran el sistema y que han sido creadas por éste en analogía con las soluciones previstas en él, o bien integran el sistema justamente en razón de haber sido creadas por el órgano de aplicación en analogía con las soluciones previstas en el sistema. Como puede apreciarse, puede admitirse la analogía en el derecho sin aceptar que ella constituya una forma de inferencia que permita derivar consecuencias a partir de las normas promulgadas. Sostener, como lo hace GuASTINI, que la analogía es admitida en ciertos sistemas jurídicos como forma de inferencia válida implica aceptar que en tales sistemas jurídicos podrían derivarse consecuencias contradictorias incluso para los casos consistentemente normados. 
En cuanto a la idea de que no todas las consecuencias lógicas de las normas explícitamente formuladas integran los sistemas jurídicos, el ejemplo que ofrece Guastinı tampoco nos parece concluyente. Supóngase un sistema jurídico que contiene dos normas, $\mathrm{N}_{1}$ y $\mathrm{N}_{2}$, de las que se sigue $\mathrm{N}_{3^{\prime}}$, norma para cuya derivación se requiere tanto de $\mathrm{N}_{1}$ como de $\mathrm{N}_{2}$, esto es, que no puede derivarse ni sólo de $\mathrm{N}_{1}$ ni sólo de $\mathrm{N}_{2}$. Supóngase adicionalmente que se promulga con posterioridad la norma $\mathrm{N}_{4}$ incompatible con $\mathrm{N}_{3}$. ¿ Implica esto necesariamente que $\mathrm{N}_{3}$ ya no puede derivarse de $\mathrm{N}_{1}$ y $\mathrm{N}_{2}$ ? Si se interpreta que no, esto significa que se entiende que la promulgación de $\mathrm{N}_{4}$ tiene repercusión sobre las reglas de inferencia admisibles en el sistema. En otras palabras, que antes de su promulgación resultaba aceptable una regla de inferencia que ya no lo es luego de haber sido promulgada. Reconstruir este ejemplo en la forma que propone GUASTINI implica -al igual que en el caso anterior- que la promulgación de una norma puede influir en la admisibilidad de nuestras reglas de inferencia. Esto nos parece demasiado drástico, sobre todo si se dispone de una alternativa de conformidad con la cual se preserva el carácter central de las reglas de inferencia en nuestros esquemas conceptuales.

En el ejemplo considerado, la alternativa al planteo antes comentado consistiría en interpretar que la promulgación de $\mathrm{N}_{4}$ no repercute sobre las reglas de inferencia sino sobre las normas que conforman el sistema. Ahora bien, si se adopta esta lectura, entonces es preciso considerar que, o bien $\mathrm{N}_{1}$ o bien $\mathrm{N}_{2}$ o bien ambas, han sido derogadas, dado que conjuntamente implican $\mathrm{N}_{3}$ que, por hipótesis, resulta incompatible con $\mathrm{N}_{4}$. Y ello conduce a la admisión de la indeterminación de los sistemas jurídicos como consecuencia de ciertos actos de derogación de normas derivadas.

Lo importante es advertir las consecuencias que se siguen de cada una de estas dos reconstrucciones. De acuerdo con la nuestra, es menester aceptar que la promulgación de una norma puede provocar la derogación de otra que no es directamente incompatible con la nueva norma promulgada. De conformidad con la interpretación de GUASTINI ello no ocurre, pero es necesario admitir que la promulgación de una norma puede tener repercusión sobre las reglas de inferencia admisibles en el sistema considerado. Si, por ejemplo, la norma $\mathrm{N}_{1}$ dispone que si es obligatorio un acto $p$, entonces es obligatorio un acto $q$, y la norma $N_{2}$ establece que es obligatorio el acto $p$, de ello parece seguirse la norma $\mathrm{N}_{3}$, según la cual es obligatorio el acto q; pero si una norma jerárquicamente superior $\mathrm{N}_{4}$ dispone que está permitido abstenerse de q, entonces habría que rechazar el modus ponens como regla de inferencia admisible en el sistema. Ello impediría en lo futuro inferir, a partir por ejemplo de una norma de tal sistema que establece 
que los homicidas deben ser sancionados y del hecho de que Juan ha cometido homicidio, que Juan debe ser sancionado. Dejamos a criterio del lector evaluar cuál de estas dos alternativas parece más difícil de aceptar.

\section{Notas}

* Este trabajo ha sido realizado con el apoyo de la Fundación Antorchas.

** Universidad Nacional de Mar del Plata.

*** Universidad de Buenos Aires. 